\title{
Thermal and Optical Characterization of Polymer-Dispersed Liquid Crystals
}

\author{
Robert A. Shanks and Daniel Staszczyk \\ School of Applied Sciences, RMIT University, GPO Box 2476, Melbourne, VIC 3001, Australia \\ Correspondence should be addressed to Robert A. Shanks, robert.shanks@rmit.edu.au
}

Received 4 August 2011; Revised 24 January 2012; Accepted 31 January 2012

Academic Editor: Wen Fu Lee

Copyright ( $) 2012$ R. A. Shanks and D. Staszczyk. This is an open access article distributed under the Creative Commons Attribution License, which permits unrestricted use, distribution, and reproduction in any medium, provided the original work is properly cited.

\begin{abstract}
Liquid crystals are compounds that display order in the liquid state above the melting temperature and below the mesogenic isotropic temperature. Polymer-dispersed liquid crystals (PDLCs) are composite materials in which liquid crystalline material is dispersed within a polymer matrix to form micron-sized droplets. The aim was to prepare several cholesteryl esters or alkoxybenzoic acid PDLCs and characterise thermal and optical properties. Differential scanning calorimetry and polarized optical microscopy were employed. The matrix polymer was a one-component UV-curable epoxy-acrylate resin. PDLCs were formed through entropy controlled phase separation resulting from UV-initiated crosslinking. The liquid crystals, both as mesogenic moieties and as dispersed droplets, exhibited various textures according to their molecular order and orientation. These textures formed in constrained regions separated by phase boundaries that occurred at temperatures characteristic of each liquid crystal used. The PDLC phase transitions occurred at temperatures lower than those exhibited by the mesogenic components in the neat state.
\end{abstract}

\section{Introduction}

Liquid crystals are unique compounds that display order in the liquid state. Liquid crystallinity is seen to occur in a region above the melting temperature $\left(T_{m}\right)$ and below the clearing temperature $\left(T_{i}\right)$. Above the clearing temperature, liquid crystal molecules will randomize to form an isotropic liquid. A material exhibiting liquid crystallinity will appear as a opaque, turbid fluid to the naked eye and under a polarizing microscope will form characteristic optical textures due to the high birefringence exhibited. Substances will generally exhibit liquid crystallinity in solution (lyotropic) or in the neat state (mesogenic). Liquid crystalline moieties (mesogens) can be incorporated into a polymer either as components of the main polymer chain or as side chains. Polymer-dispersed liquid crystals are formed when liquid crystalline material is dispersed within a polymer matrix.

The intermediate phases that liquid crystals exhibit during transitions from the solid to isotropic liquid are known as "mesophases." Translational and rotational order is responsible for partial ordering within mesophases. Trans- lational order is evident regardless of molecular shape whereas rotational order is apparent only when the molecules are nonspherical (elongated). Molecular shape will therefore be a factor that influences the ordering of a particular mesophase [1]. Disordered crystal mesophases are known as plastic crystals and are those with a 3-dimensional crystal lattice that exhibit a considerable amount of rotational disorder. The mesophases in disordered liquid crystals are translationally well ordered but rotationally disordered; therefore once the temperature is increased and sufficient energy is provided to overcome the rotational energy barriers, a mesophase is exhibited until sufficient energy is provided to disrupt the lattice resulting in the formation of an isotropic liquid.

The classification of mesophases exhibited by liquid crystals is based largely on the symmetry of the molecules. The three major classes are the nematic, cholesteric, and smectic. All differ in the extent of lattice order within the mesophase [2]. Nematic liquid crystals can translate in any direction relative to their neighbours but tend to align themselves parallel to one another along the principle axis 
(n). The direction of the principle axis is arbitrary within a mesophase.

Cholesteric structure occurs when there is a "twisting" of the nematic director between successive layers. The cholesteric director $(n)$ follows a helix of the form [1]

$$
\begin{gathered}
n_{x}=\cos \left(q_{o} z+\alpha\right), \\
n_{y}=\sin \left(q_{o} z+\alpha\right), \\
n_{z}=0 .
\end{gathered}
$$

The direction of the phase angle $(\alpha)$ and helix axis $(z)$ are arbitrary, and therefore the spatial period of the cholesteric structure can be given by [1]

$$
L=\frac{\pi}{\left|q_{o}\right|} .
$$

The sign of $q_{o}$ represents either a left or a right helix while the magnitude will determine the spatial period of the structure [1].

The nematic mesophase is regarded as being in the same group as the cholesteric because it is simply a cholesteric with $q_{o}=0$.

Three of the most common smectic phases are the smectic A, C, and B phases. Molecules within smectic phases lie parallel with their neighbours in layers, and translational motion between the layers does not occur readily. The layered structure of smectic phases reduces their viscosity in comparison to the nematic or cholesteric phases. Molecules within smectic mesophases tend to align themselves parallel to the layer normal, and their centre of mass positions is uncorrelated. The layers are found to be individually fluid with a high probability of interlayer diffusion occurring. Xray scattering is used to determine that the molecular length of liquid crystals is essentially equal to that of the thickness of the layers [1].

Polymorphism is the ability of a liquid crystal to pass through a number of mesophases between the solid and isotropic states. Because increasing temperature reduces the molecular ordering of mesophases, it is possible to determine the relative positions of a mesophases based on their order of stability. The order of stability is shown below for the phases discussed previously, and these are in agreement with experimental data. Polymorphism involving both the nematic and cholesteric phases has not been observed [1].

Polarized optical microscopy is used to view the optical patterns or textures of liquid crystalline material, and in some instances the particular order of the mesophase can be identified. Identification of mesophases in this manner is not always possible due to similar textures sometimes observed between two liquid crystal states separated by a phase change [3]. Anisotropic materials such as liquid crystals have optical properties that change depending on the orientation of incident light with the crystallographic axis. The propagation direction of light through an anisotropic substance and the vibrational plane coordinates will determine the range of refractive indices. Light polarized parallel to the director has a different index of refraction than light polarized perpendicular to the director. Light entering the liquid crystal is separated into fast (ordinary ray) and slow (extraordinary ray) components. A phase difference occurs as a result of the components travelling at different velocities and a new polarization state is created [4].

The cooling curve obtained through DSC for a liquid crystalline material is characterized by a high-temperature exotherm representing a first-order transformation from an isotropic liquid to a mesophase and a low-temperature exotherm indicating the first-order transformation of the mesophase to the solid state. For the heating curve, the transition temperatures are found to be slightly higher than the equivalent temperatures on the cooling curve as would be expected because once an isotropic liquid has been reached it takes time for the molecules to rearrange themselves into an ordered structure. In a liquid crystal where polymorphism is seen to occur, DSC can be used to distinguish between the nematic and smectic phases based on the magnitude of the enthalpy change accompanying the transition to the isotropic phase. A small enthalpy change for a transition between mesophases indicates a close structural relationship between the two phases [5].

Long range ordering within a mesophase is expected to occur more readily with molecules that are nonspherical (rod-like shape). Mesophases are favoured by molecules that display rigidity, permanent dipoles, and polarizability [2]. Virtually all mesogens consist of multiple bonds along their axis, aromatic components, and either polar or long-chain terminal groups. The terminal group will very often determine the nature of the mesophase exhibited [2]. In general, if the terminal group is short and flexible, the compound will display smectic order whereas if it is long, the nematic order will be observed [6].

Dipole-dipole (permanent and induced) and dispersion forces are the main forces responsible for mesophase stability. For example, the nematic $\rightarrow$ isotropic transition of 4octyloxybenzoic acid [7] is about $40^{\circ} \mathrm{C}$ higher than that of 4-nonylbenzoic acid [8] even though the two molecules are essentially the same size [2]. Similarly, mesophases formed by 4 -alkoxy-4'-cyanobiphenyls are more stable than those formed by 4 -alkyl-4' -cyanobiphenyls $[2,9]$.

Intermolecular polar attractions are required if a mesophase is to remain intact once the lattice energy of the structure has been reached [2]. The melting temperature can be raised to a temperature where the mesophase cannot exist if a situation occurs where the intermolecular forces are too strong due to polarity at the terminal groups. An example of this is 6-hydroxy-2-naphthoic acid (crystal $\rightarrow$ isotropic $=250^{\circ} \mathrm{C}$ ) whose end group polarity is higher than that of 6-methoxy-2-naphthoic acid (crystal $\rightarrow$ nematic $=206^{\circ} \mathrm{C}$; nematic $\rightarrow$ isotropic $=219^{\circ} \mathrm{C}$ ) $[10]$.

Central groups that provide linearity to the shape of the molecule have been found to increase the thermal stability as the polarity or polarisability increases for the central linkage component [11]. It has been shown that, in the absence of a central group that provides linearity or at the least planarity, the mesophase stability decreases $[2,11,12]$.

Another property that affects the stability of a given mesophase is the molecular breadth. An increase in the molecular breadth occurs mainly due to substitution on the 
aromatic rings. A larger molecular breadth normally reduces the liquid crystallinity of a material, the smectic phase often being effected to a greater extent $[2,5]$.

Polymer-dispersed liquid crystals (PDLCs) are composite materials in which liquid crystalline material is dispersed within a polymer matrix to form micron-sized droplets. PDLC films have a variety of electrooptical applications ranging from window shutters to projection displays. The thermal and mechanical stability of thermooptical devices are improved by dispersing a liquid crystalline material within a polymer matrix $[13,14]$. The liquid crystal texture within a dispersed droplet is randomly orientated relative to other droplets giving the PDLC film an opaque appearance due to the strong scattering of light that occurs. When an electric field is applied, the directors of each droplet align parallel to the applied field, and if the refractive index of the liquid crystal is matched to that of the polymer, then the film becomes optically transparent [13-15].

PDLC can be produced using methods such as encapsulation and phase separation. Encapsulation is when the liquid crystal is mixed with a polymer dissolved in water that is then evaporated leaving the liquid crystal surrounded by a layer of polymer. PDLCs prepared by phase separation require a homogeneous mixture of polymer (prepolymer) and liquid crystal to be prepared initially followed by the separation of the two phases to create the liquid crystal droplets. Phase separation can be induced in the following ways.

Polymerization-induced phase separation (PIPS) occurs when liquid crystals are mixed with a prepolymer to form a homogeneous solution. When polymerization is initiated, the molecular weight and crosslinking of the polymer increase and hence the solubility of the liquid crystal decreases leading to the formation of droplets.

Thermally induced phase separation (TIPS) is when a homogeneous mixture of liquid crystal and a melted polymer is cooled. Liquid crystal droplets continue to form as the polymer hardens until the glass transition temperature is reached.

Solvent-induced phase separation (SIPS) is when the liquid crystal and polymer are dissolved in a solvent prior to the solvent being removed, generally by evaporation. Liquid crystal droplets form as the polymer and liquid crystal separate from the solution.

Polymerization-induced phase separation is the most commonly used. This procedure was used to make the PDLC in this work with polymerization being initiated using UV light.

Complete phase separation does not always occur between the two components. A small fraction of mesogen remains in the polymer matrix, while prepolymer or partially cured polymer is present in small amounts in the liquid crystal droplets $[15,16]$. Incomplete phase separation has several significant effects on the properties of the PDLC. Low-molecular-weight liquid crystals will generally act as a plasticizer in a polymer matrix and hence reduce the glass transition temperature of the matrix $[15,17]$. The liquid crystal can cause a change in the refractive index of the polymer matrix, which in turn would lead to less clarity in the transparent state when an electric field is applied

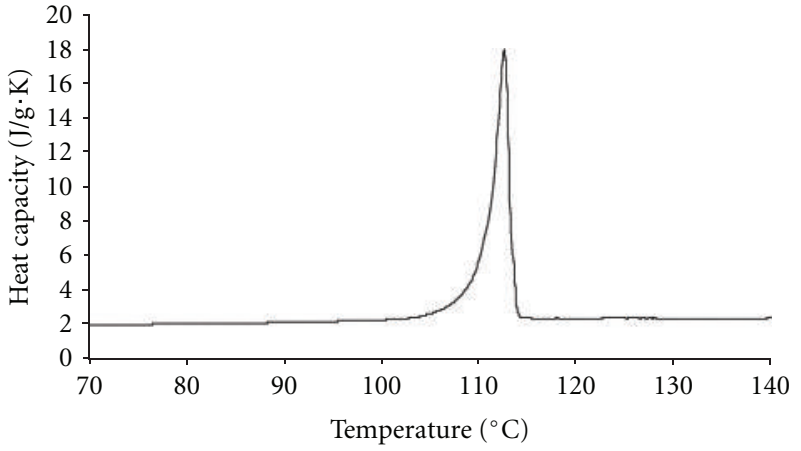

(a)

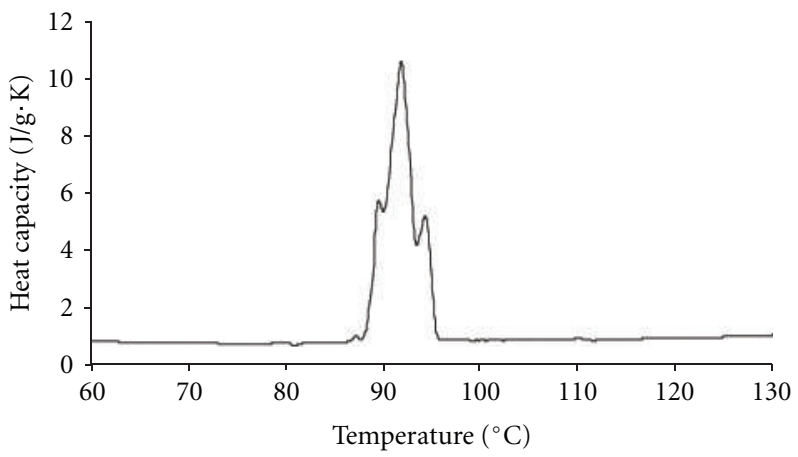

(b)

FIGURE 1: DSC thermograms of cholesteryl acetate at a rate of $10 \mathrm{~K} \cdot \mathrm{min}^{-1}$, (a) heating, (b) cooling.

[15]. A prepolymer or partially cured polymer present in the liquid crystal droplets leads to a reduction in the clearing temperature. For phase separation that was induced using UV light, the presence of an initiator in the liquid crystal droplets would have a similar effect [15].

The morphology of liquid crystal droplets is affected by many variables, the principle factors being liquid crystal and polymer composition, cure temperature, and the rate of curing. The growth of liquid crystal droplets requires diffusion of liquid crystal material towards and diffusion of monomer and polymer away from the droplet and movement of the droplet boundary into the polymer-rich boundary [18]. Once curing has been initiated and the molecular weight of the polymer matrix begins to increase, elasticity and viscosity increase making the growth of the droplets more difficult [14].

The viscosity of a polymer is important in determining to what degree a mesogen experiences coalescence. In the absence of coalescence, the liquid crystal morphology of the droplets is seen to be much more uniform and spherical in appearance [19]. When coalescence occurs, elliptical shaped domains form as the polymer matrix solidifies preventing the formation of spherical domains. Allowing a mixture to coalesce more readily (either through increasing temperature or decreasing the rate of cure) will result in the formation of larger liquid crystal domains [14, 17, 19, 20]. Lowering the rate of cure (reduced UV intensity) results in slowing the hardening of the polymer matrix once phase separation has 


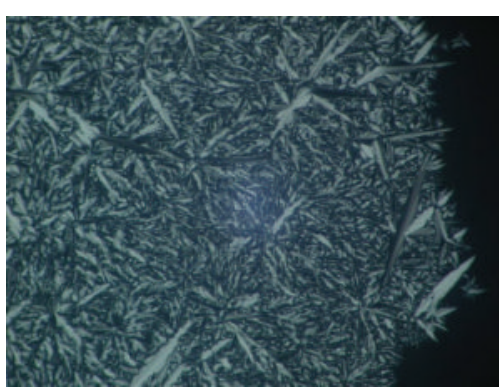

(a)

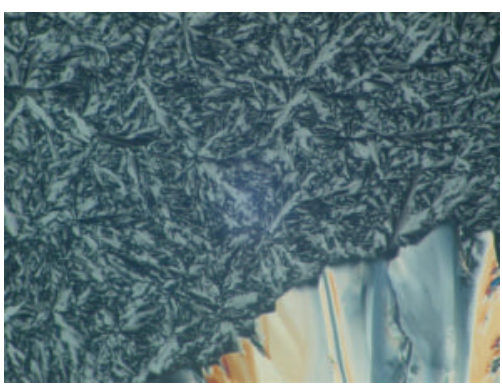

(b)

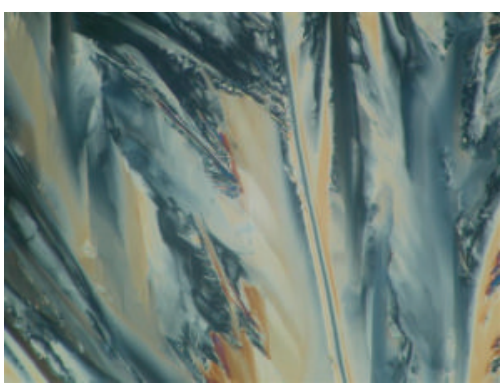

(c)

FIgURe 2: Polarized optical micrographs of cholesteryl acetate taken during cooling from the isotropic phase at (a) $93.9^{\circ} \mathrm{C}$, (b) $93.7^{\circ} \mathrm{C}$, and (c) $25^{\circ} \mathrm{C}$.

been induced, giving the mesogen more time to coalesce and form larger droplets [21]. Coalescence occurs more readily in a less viscous solution so by increasing the temperature (decreasing viscosity) coalescence increases and the liquid crystal droplet size will increase $[17,19]$. However, it should be noted that previous studies such as those carried out by Carter et al. [19] show the cure temperature to have a negligible effect on liquid crystal droplet size compared with factors such as the cure rate and composition that have a significant effect. An increase in the liquid crystal fraction is also expected to increase the droplet size $[19,20]$. This is thought to occur because of the difference in the extent of polymerisation at the phase separation stage that allows for larger liquid crystal domains due to the less developed polymer matrix. It has also been shown that the presence of an electric field during the phase separation process promotes the alignment of the liquid crystal molecules, which results in a strengthening of the phases separation process [14]. The phases separation process is accelerated by the electric field and the clearing temperature of the PDLC rise [14].

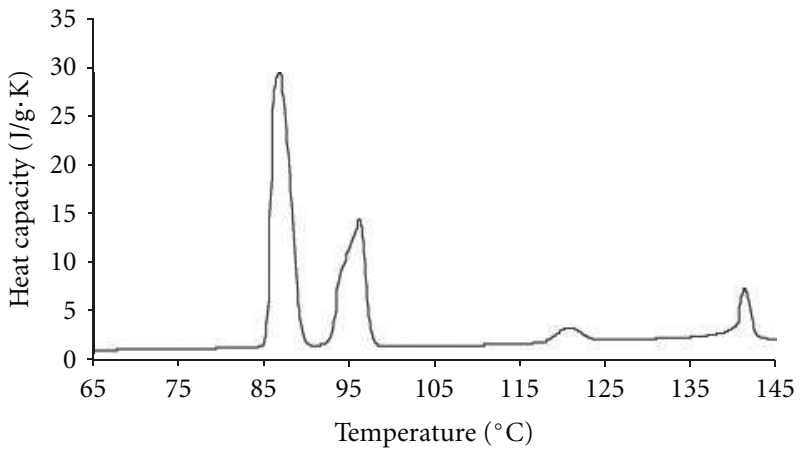

(a)

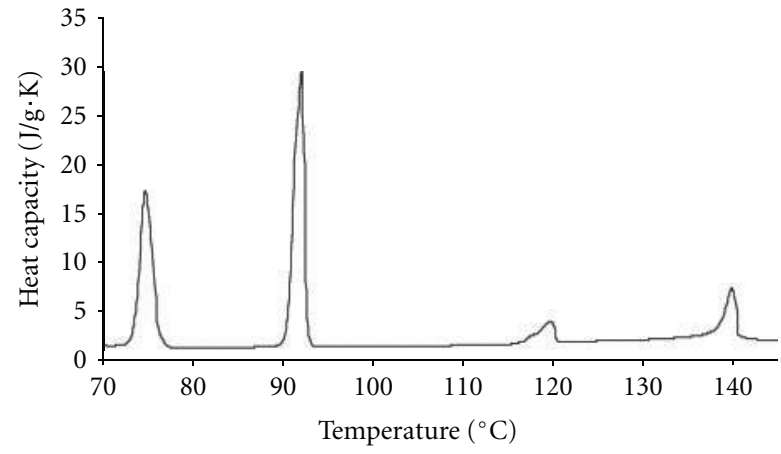

(b)

Figure 3: DSC thermograms of 4-(decyloxy)benzoic acid at a rate of $10 \mathrm{~K} \cdot \mathrm{min}^{-1}$, (a) heating, (b) cooling.

The aim of this research is to prepare and characterise polymer-dispersed liquid crystals in an ultraviolet cured polymer matrix. The thermal and optical behaviour of the liquid crystal are investigated using differential scanning calorimetry (DSC) and hot-stage polarized optical microscopy. The thermal properties obtained from DSC will be coupled with polarized optical microscopy to investigate the polymerisation-induced phase separation and liquid crystal textures over temperature domains.

\section{Experimental}

2.1. Materials. The mesogens used were cholesteryl acetate, cholesteryl nonanoate, cholesteryl benzoate, and 4-(decyloxy)benzoic acid, all except cholesteryl benzoate were purchased from Sigma Aldrich. Cholesteryl benzoate was synthesized from benzoyl chloride (Sigma Aldrich) and cholesterol (Sigma Aldrich) using chloroform as a solvent and it was recrystallized from ethanol.

The polymer used was Master Bond UV15 (UV15), a one component ultraviolet (UV) curable epoxy-acrylate resin. UV15 exhibits low viscosity at room temperature and does not contain any solvents or other volatiles.

2.2. Polymer-Dispersed Liquid Crystal Preparation. Prepolymer and mesogen were weighed in small vials and then mixed thoroughly to give homogenous blends. The blends were prepared to give approximately $20 \% \cdot \mathrm{w} / \mathrm{w}$ mesogen. The 


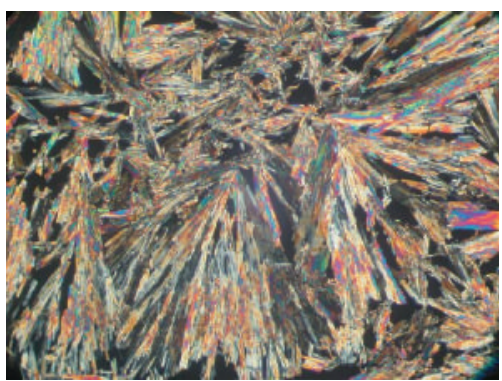

(a)

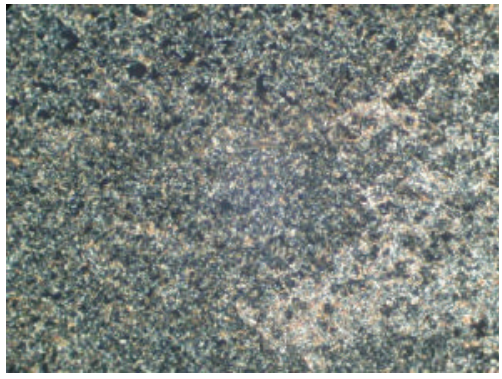

(b)

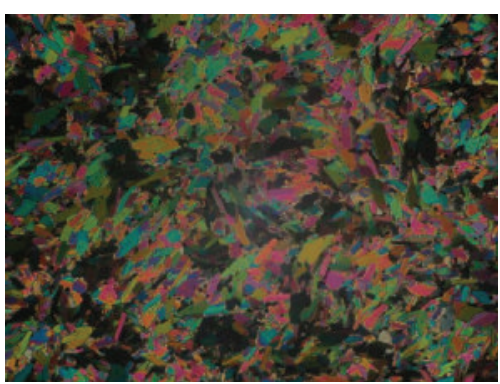

(c)

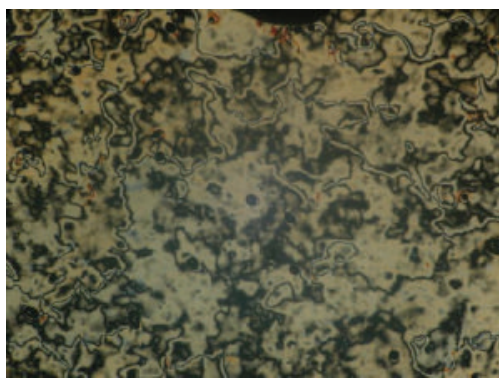

(d)

Figure 4: Polarized optical micrographs of 4-(decyloxy)benzoic acid taken during heating from the solid phase at (a) $25^{\circ} \mathrm{C}$, (b) $91.4^{\circ} \mathrm{C}$, (c) $106.8^{\circ} \mathrm{C}$, and (d) $135.2^{\circ} \mathrm{C}$.

mixtures were then subsequently cured either in a DSC pan or as a thin film on a microscope slide. Curing was achieved by exposure to $\mathrm{UV}$ radiation $\left(3 \mathrm{~mW} \cdot \mathrm{cm}^{-2}\right)$ for $10 \mathrm{~min}$ to ensure full cure. The temperature of each film was raised above the clearing temperature before being sandwiched between two glass plates. The films were allowed to cool to room temperature prior to any observation using an optical microscope.

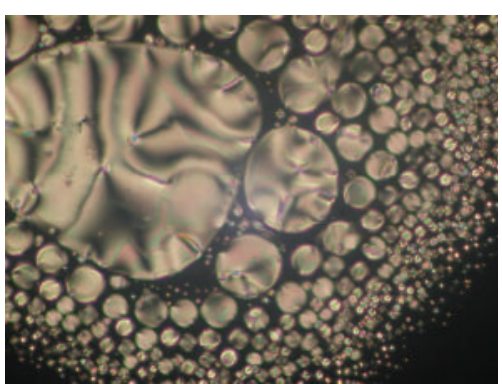

(a)

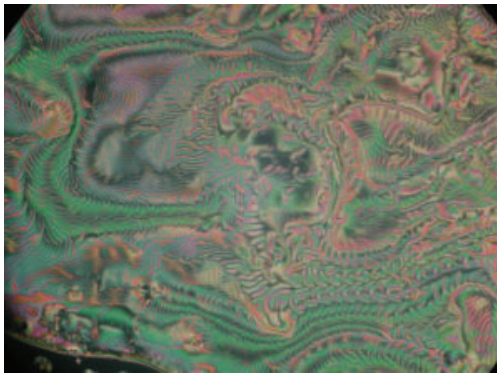

(b)

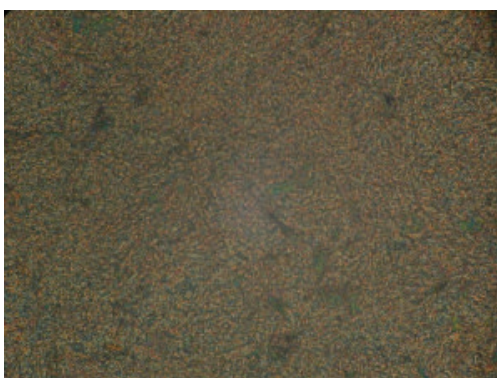

(c)

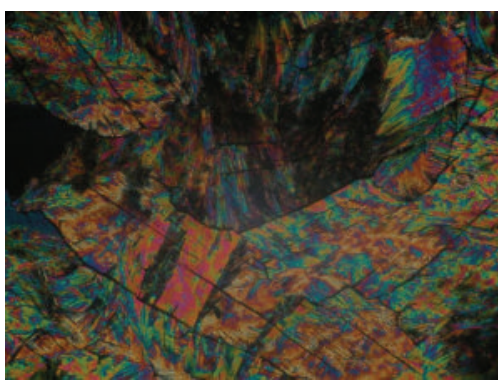

(d)

Figure 5: Polarized optical micrographs of 4-(decyloxy)benzoic acid taken during cooling from the isotropic phase at (a) $129.5^{\circ} \mathrm{C}$, (b) $108.8^{\circ} \mathrm{C}$, and (c) $82.9^{\circ} \mathrm{C}$, (d) $25^{\circ} \mathrm{C}$.

2.3. Differential Scanning Calorimetry. A Perkin-Elmer DSC7 with Pyris software (version 3.81) was used. An icewater slurry was used as coolant and a nitrogen purge $\left(20 \mathrm{~mL} \cdot \mathrm{min}^{-1}\right)$ was used. Sample masses of about $2 \mathrm{mg}$ for pure mesogens and $6 \mathrm{mg}$ for PDLC were accurately weighed using a Perkin-Elmer AD-2Z microbalance. The mesogens and PDLC were encapsulated in hermetically sealed aluminium pans of $10 \mu \mathrm{L}$ and $30 \mu \mathrm{L}$ volume, respectively. All samples were heated to a temperature above the expected 


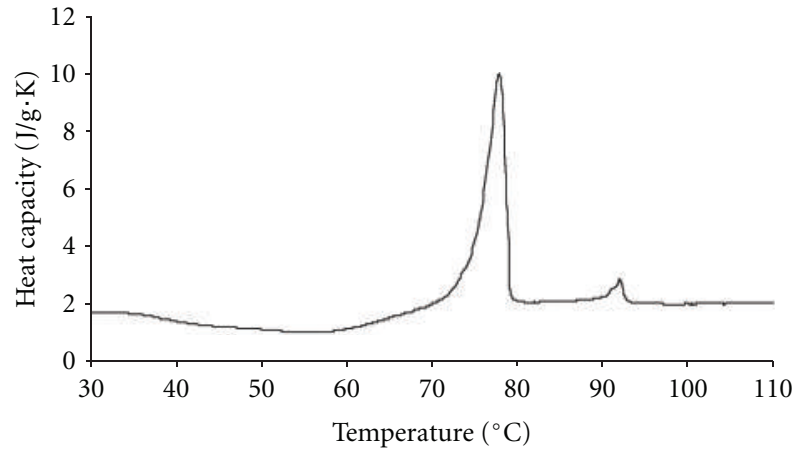

(a)

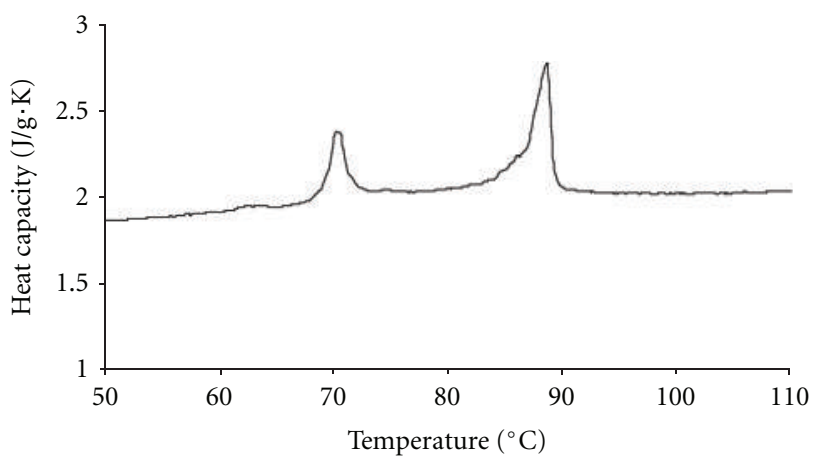

(b)

Figure 6: DSC thermograms of cholesteryl nonanoate at a rate of $10 \mathrm{~K} \cdot \mathrm{min}^{-1}$, (a) heating, (b) cooling.

clearing temperature and held isothermally. Once a stable heat flow was observed, the samples were cooled at a rate of $10 \mathrm{~K} \cdot \mathrm{min}^{-1}$ to $25^{\circ} \mathrm{C}$ followed by a heating scan at a rate of $10 \mathrm{~K} \cdot \mathrm{min}^{-1}$ to a temperature above the expected clearing temperature. All curves were corrected using baselines recorded under identical conditions and converted to apparent specific heat capacity curves.

2.4. Optical Microscopy. Polarized optical microscopy was used to observe the thermal behaviour and textures exhibited by the mesophases. A Nikon Labophot II optical microscope equipped with a Mettler FP90 central processor and FP82 hot stage was used. Images were captured using a Nikon digital camera during heating or cooling at rates of $2 \mathrm{~K} \cdot \mathrm{min}^{-1}[4]$.

\section{Results and Discussion}

\subsection{Pure Liquid Crystals}

3.1.1. Cholesteryl Acetate. The DSC heating scan for cholesteryl acetate shown in Figure 1 (a) shows a peak at $112.5^{\circ} \mathrm{C}$ corresponding to the melting transition. A mesophase region was not identified during heating, either by DSC or by polarized optical microscopic observation. Polarized optical microscopy showed the transition from the solid phase directly to the isotropic phase (seen as a dark field of view). The DSC cooling scan for cholesteryl acetate shown in Figure 1(b) shows the crystallization temperature to have

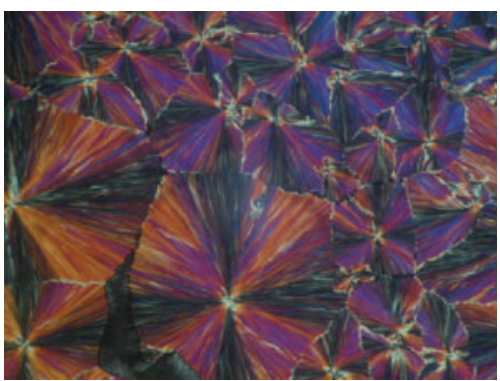

(a)

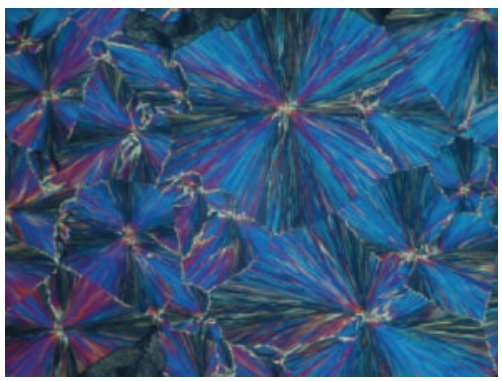

(b)

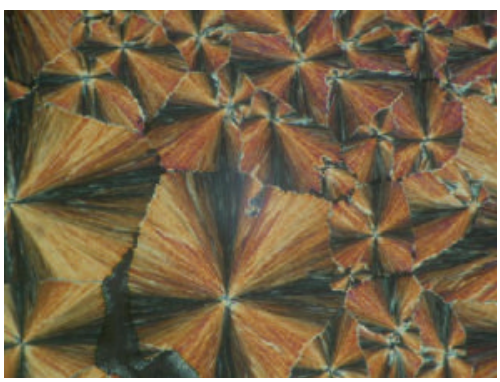

(c)

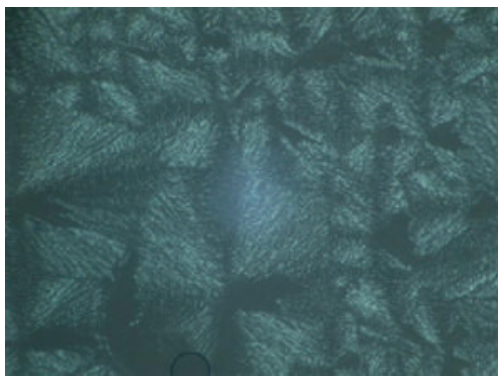

(d)

Figure 7: Polarized optical micrographs of cholesteryl nonanoate taken during heating from the solid phase at (a) $25^{\circ} \mathrm{C}$, (b) $55^{\circ} \mathrm{C}$, (c) $72{ }^{\circ} \mathrm{C}$, and (d) $85^{\circ} \mathrm{C}$.

undergone supercooling to $91.1^{\circ} \mathrm{C}$. A smaller peak at $94.6{ }^{\circ} \mathrm{C}$ on the shoulder of the melting peak corresponds to the transition from the mesophase to isotropic phase. Through polarized optical microscopy and reference to literature [5], the mesophase texture was identified as being a disturbed cholesteric texture as shown in Figure 2(a). Figure 2(b) shows the transition from the disturbed cholesteric texture to the solid phase, which exhibits a marble like texture as is shown in Figure 2(c). 


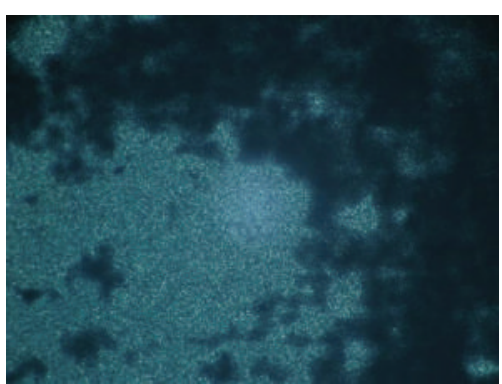

(a)

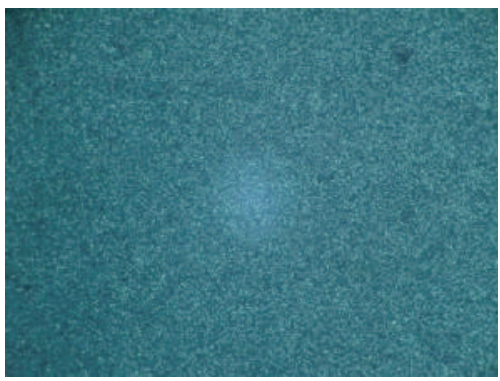

(b)

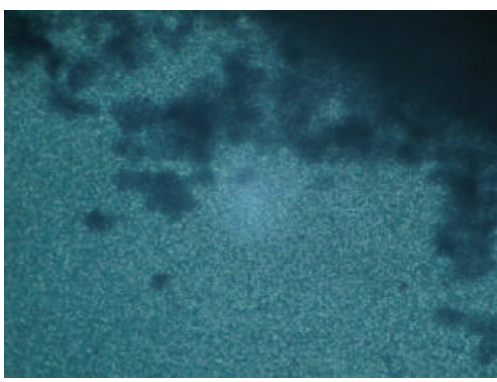

(c)

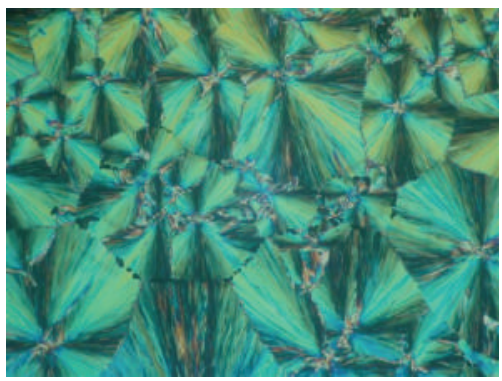

(d)

Figure 8: Polarized optical micrographs of cholesteryl nonanoate acid taken during cooling from the isotropic phase at (a) $90.2{ }^{\circ} \mathrm{C}$, (b) $80.7^{\circ} \mathrm{C}$, (c) $69.9^{\circ} \mathrm{C}$, and (d) $25^{\circ} \mathrm{C}(20$ min annealing).

3.1.2. 4-(Decyloxy)benzoic Acid. 4-(Decyloxy)benzoic acid exhibited polymesomorphism on both heating and cooling. The DSC heating scan (Figure 3) identified three mesophase regions at $86.4^{\circ} \mathrm{C}$ to $96.1{ }^{\circ} \mathrm{C}, 96.1{ }^{\circ} \mathrm{C}$ to $120.2{ }^{\circ} \mathrm{C}$, and $120.3^{\circ} \mathrm{C}$ to $130.9^{\circ} \mathrm{C}$, which were identified using Sigma Aldrich data as smectic, smectic, and nematic phases, respectively. Polarized optical microscopic images shown in Figure 4(a) show the solid phase prior to heating, while Figures 4(b) and 4(c) show the two different smectic phases at $91.4{ }^{\circ} \mathrm{C}$ and $106.8^{\circ} \mathrm{C}$ respectively. Figure $4(\mathrm{~d})$ is an image

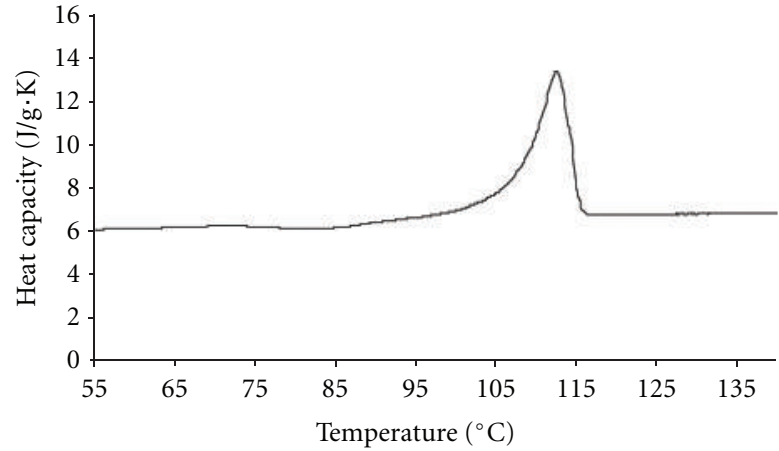

(a)

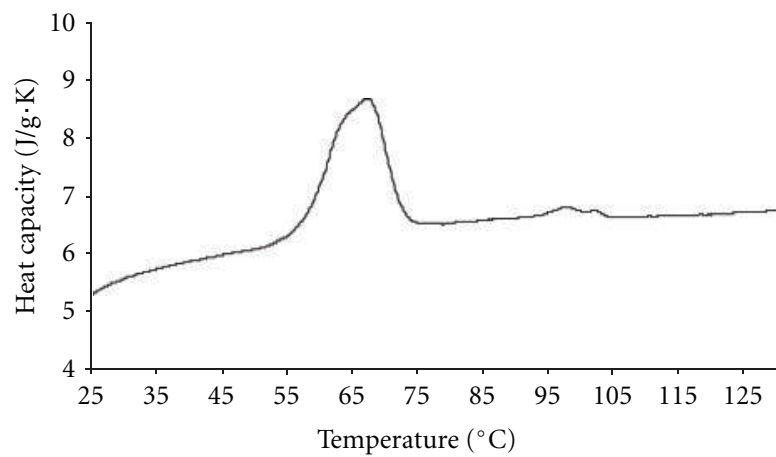

(b)

Figure 9: DSC thermograms of cholesteryl benzoate at a rate of $10 \mathrm{~K} \cdot \mathrm{min}^{-1}$, (a) heating, (b) cooling.

taken in the nematic region at $135.2^{\circ} \mathrm{C}$ and was identified as a marbled nematic texture. Marbled textures are seen when differing molecular orientations within adjoining domains cause light scattering of different colours that impart a granular appearance to the texture.

The DSC cooling scan (Figure 3) identified three mesophase regions where the transitions accompanying phase changes were seen to exhibit supercooling with respect to transitions during heating. Due to a difference in the degree of supercooling experienced by each transition, the temperature range over which each mesophase was exhibited changed considerably in comparison with those on heating. On cooling, the DSC identified three mesophase regions at $139.8^{\circ} \mathrm{C}$ to $118.8^{\circ} \mathrm{C}, 118.8^{\circ} \mathrm{C}$ to $91.9^{\circ} \mathrm{C}$, and $91.9^{\circ} \mathrm{C}$ to $75.1^{\circ} \mathrm{C}$, which, using Sigma Aldrich data, were identified as nematic, smectic, and smectic phases, respectively. The textures of these mesophases were identified using polarized optical microscopy and are shown below in Figure 5. Figure 5(a) shows Schlieren droplets at $129.5^{\circ} \mathrm{C}$ separating from the isotropic liquid (seen as a dark field of view) and coalescing together to form larger droplets $[3,5]$. The dark "brush" patterns in Schlieren textures correspond to the extinction zones where the mesogens align perpendicular to the substrate. Generally, Schlieren textures that show points where only two brushes meet are nematic while those that show points where four brushes meet are smectic. The image in Figure 5 (b) taken at $108.8^{\circ} \mathrm{C}$ was identified as a twisted smectic texture normally associated with smectic C 


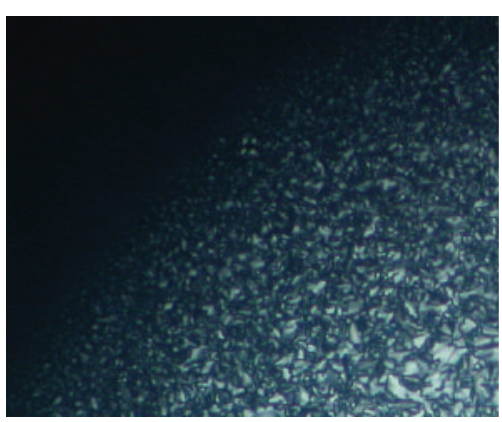

(a)

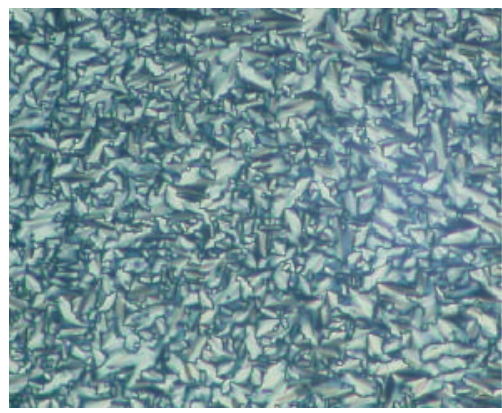

(b)

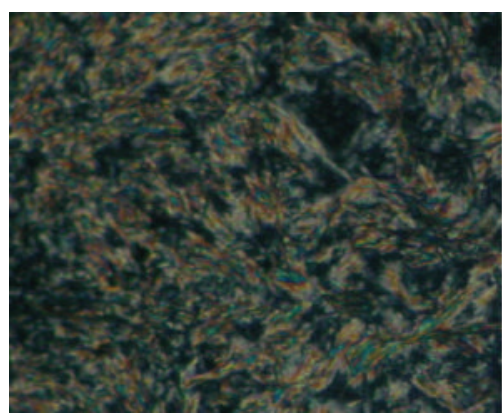

(c)

Figure 10: Polarized optical micrographs of cholesteryl benzoate taken during cooling from the isotropic phase at (a) $101.1^{\circ} \mathrm{C}$, (b) $98.8^{\circ} \mathrm{C}$, and (c) $25^{\circ} \mathrm{C}$.

type ordering [3]. The image shown in Figure 5(c) is an unidentified smectic texture at $82.9^{\circ} \mathrm{C}$, and Figure $5(\mathrm{~d})$ is an image of the solid phase at room temperature after cooling.

3.1.3. Cholesteryl Nonanoate. The DSC heating scan for cholesteryl nonanoate shown in Figure 6(a) shows a peak at $75.8^{\circ} \mathrm{C}$ corresponding to the melting temperature and smaller peak at $92.7^{\circ} \mathrm{C}$ representing the clearing temperature. Polarized optical microscopy showed the colour of the solid phase to change with an increase in temperature as shown in Figures $7(\mathrm{a})-7(\mathrm{c})$. This is most likely due to restricted movement of the molecules within the lattice structure as energy in the form of heat was supplied to the system. Figure $7(\mathrm{~d})$ shows the mesophase at $85^{\circ} \mathrm{C}$, which according to Sigma Aldrich data is of cholesteric order.

The DSC cooling scan for cholesteryl nonanoate shown in Figure 6(b) shows the clearing temperature to have undergone slight supercooling to $88.5^{\circ} \mathrm{C}$ and a phase transition

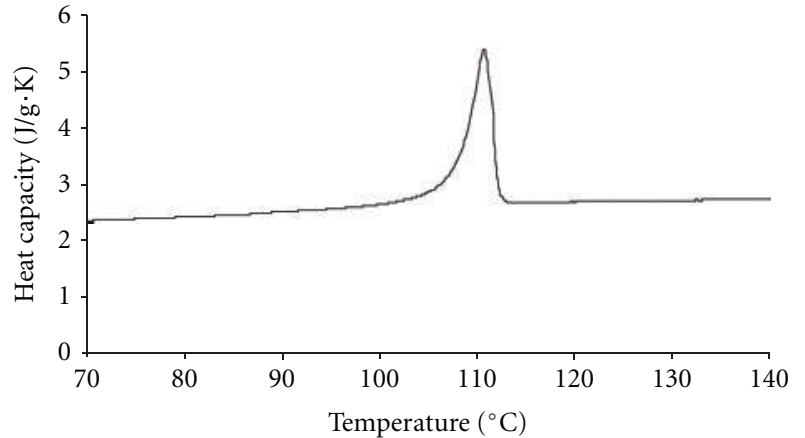

(a)

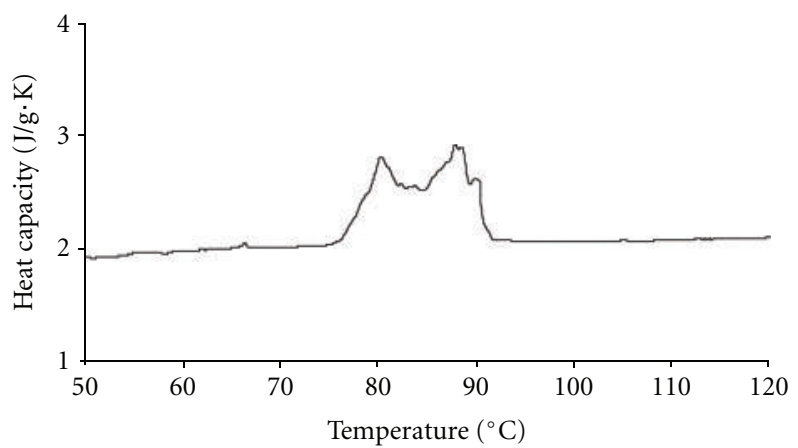

(b)

FIGURE 11: DSC thermograms for cholesteryl acetate dispersed in UV15 at scanning rate of $10 \mathrm{~K} \cdot \mathrm{min}^{-1}$, (a) heating, (b) cooling.

at $70.3^{\circ} \mathrm{C}$. Figure 8 shows images taken during cooling using polarized optical microscopy. Figures $8(\mathrm{a})$ and $8(\mathrm{~b})$ show the transition from the isotropic liquid (seen as the dark field view) to the mesophase. Using data provided by Sigma Aldrich, this mesophase was identified as smectic. Figure 8(c) shows the transition from the smectic texture to a homeotropic texture (seen as a dark field of view). When the surface energy of a substrate is lower than the liquid crystal surface tension a homeotropic texture will often be observed [5]. This texture is due to the long axis of the molecules aligning perpendicular to the glass substrate. The homeotropic texture and isotropic liquid were distinguished from each other (both are represented by dark field of views) by touching the glass cover. In the case of the homeotropic texture, the field of view brightened suddenly and the dark field of view reestablished once a mechanically stable state was observed. The homeotropic-to-solid transition most likely did not show a peak in the DSC curve due to it occurring after the scan had finished. Figure 8(d) shows the solid phase after annealing for $20 \mathrm{~min}$.

3.1.4. Cholesteryl Benzoate. The DSC heating scan for cholesteryl benzoate shown in Figure 9(a) shows a peak at $112.6^{\circ} \mathrm{C}$ corresponding to the melting temperature. A mesophase region was not identified during heating, either through DSC or through polarized optical microscopic observation. Polarized optical microscopy showed the transition from the solid phase directly to the isotropic phase (seen as a dark field of view). 


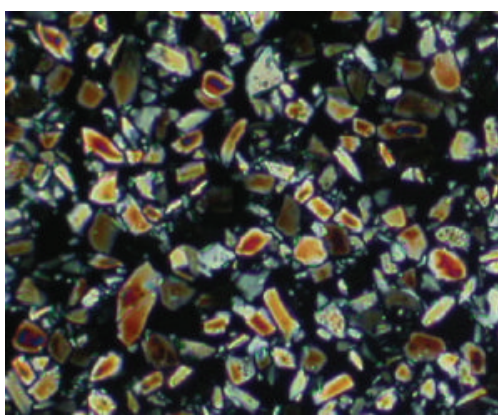

(a)

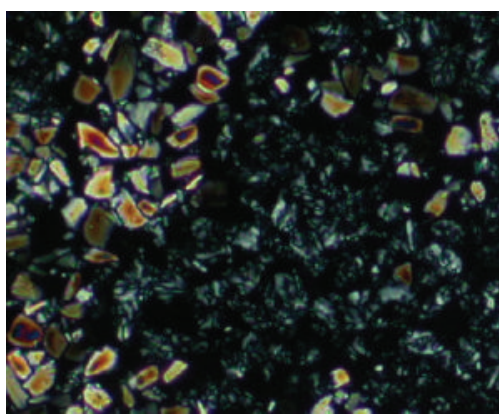

(b)

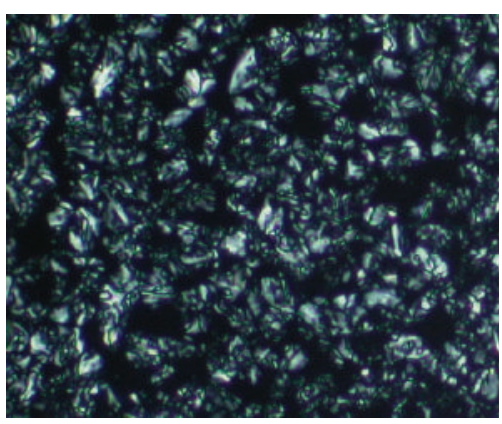

(c)

Figure 12: Polarized optical micrographs of cholesteryl acetate dispersed in UV15 taken during heating from the solid phase at (a) $25^{\circ} \mathrm{C}$, (b) $110.1^{\circ} \mathrm{C}$, and (c) $111.2^{\circ} \mathrm{C}$.

The DSC cooling scan for cholesteryl benzoate shown in Figure 9 (b) shows a peak at $67.2^{\circ} \mathrm{C}$ corresponding to the crystallization temperature that underwent substantial supercooling. The small peak at $102.2{ }^{\circ} \mathrm{C}$ corresponds to the clearing temperature. Observation using the polarized optical microscope identified the mesophase texture as a disturbed cholesteric texture. Figures 10(a) and 10(b) show the formation of the mesophase from the isotropic liquid at $101.1^{\circ} \mathrm{C}$ and $98.8^{\circ} \mathrm{C}$, respectively. Figure $10(\mathrm{c})$ is an image of the solid phase at room temperature after cooling.

\subsection{Polymer-Dispersed Liquid Crystals}

3.2.1. Cholesteryl Acetate: UV15. The DSC heating scan for cholesteryl acetate dispersed in UV15 shown in Figure 11(a) shows a single peak at $110.8^{\circ} \mathrm{C}$ corresponding to the melting temperature of the solid crystal domains. A peak for the

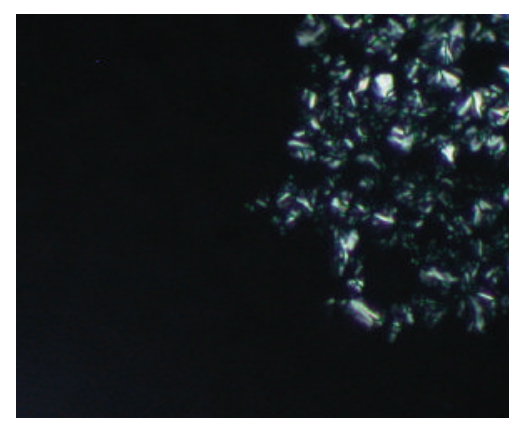

(a)

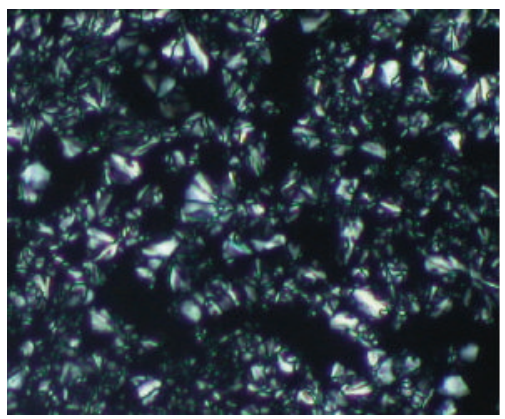

(b)

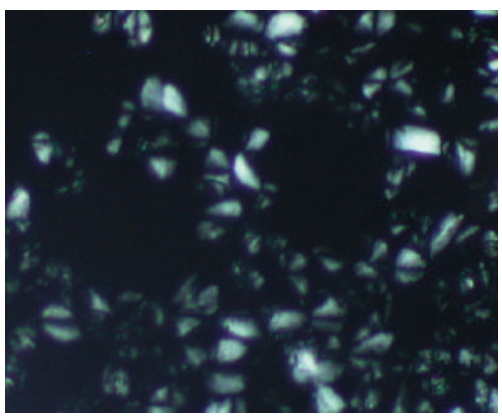

(c)

FIGURE 13: Polarized optical micrographs of cholesteryl acetate dispersed in UV15 taken during cooling from the isotropic phase at (a) $90.4^{\circ} \mathrm{C}$, (b) $71.6^{\circ} \mathrm{C}$, and (c) $25^{\circ} \mathrm{C}$.

clearing temperature cannot be seen as it is overlapping with the melting peak. Optical microscopy showed the dispersed liquid crystal domains to be approximately uniform in size and shape. Figure 12(a) shows cholesteryl acetate dispersed in UV15 at room temperature prior to heating. The dark region represents the polymer matrix while the coloured regions represent the dispersed solid crystal domains. Figures $12(\mathrm{~b})$ and $12(\mathrm{c})$ show the transition from solid to the mesophase at $110.1{ }^{\circ} \mathrm{C}$ and $111.2^{\circ} \mathrm{C}$, respectively. A dark field of view was exhibited once the isotropic region was reached.

The DSC cooling scan for cholesteryl acetate dispersed in UV15 shown in Figure 11 (b) shows peaks at $88.6^{\circ} \mathrm{C}$ and $80.1{ }^{\circ} \mathrm{C}$ corresponding to the clearing temperature and crystallization temperature, respectively, both of which underwent supercooling, due to confinement of mesogen in the dispersed droplets. Confinement of mesogen in microdroplets will result in some mesogen being adsorbed onto the epoxy matrix as an interphase with consequent supercooling 


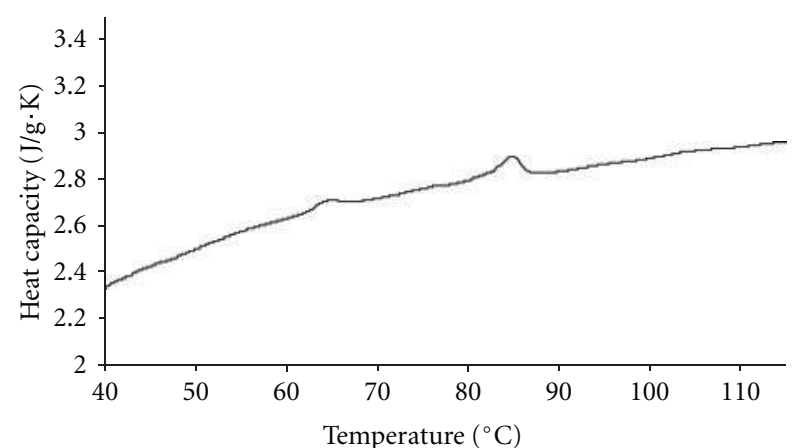

(a)

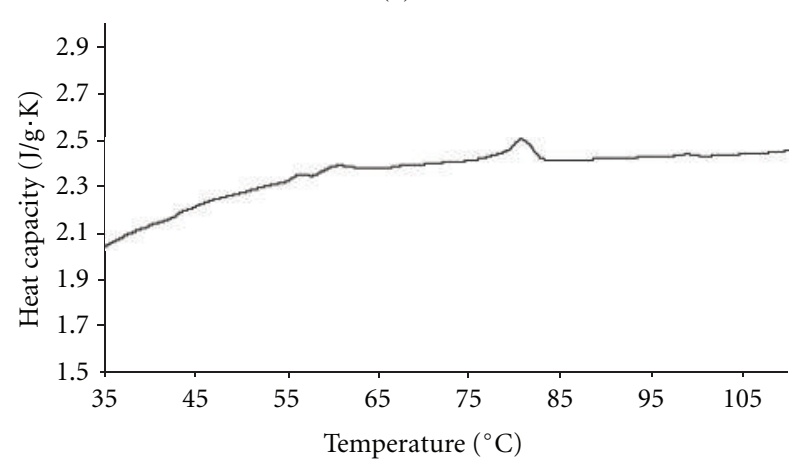

(b)

FIGURE 14: DSC thermograms for cholesteryl nonanoate dispersed in UV15 at scanning rate of $10 \mathrm{~K} \cdot \mathrm{min}^{-1}$, (a) heating, (b) cooling.

at transitions. Figures $13(\mathrm{a})$ and $13(\mathrm{~b})$ at $90.4^{\circ} \mathrm{C}$ and $71.6^{\circ} \mathrm{C}$, respectively, show polarized optical microscope images of the transition from isotropic liquid domains to liquid crystal domains. The same mesophase textures were observed on heating and cooling. Figure 13(c) shows the solid crystal domains at room temperature after cooling. These solid crystal domains are seen to contain spherulites.

3.2.2. Cholesteryl Nonanoate: UV15. The DSC heating scan for cholesteryl nonanoate dispersed in UV15 is shown in Figure 14 (a) and shows peaks at $64.5^{\circ} \mathrm{C}$ and $84.6^{\circ} \mathrm{C}$, which correspond to the melting temperature and clearing temperature, respectively. Observation using the polarized optical microscope showed the dispersed liquid crystal domains to be approximately uniform in size and shape, similar to those seen in the cholesteryl acetate-UV15 PDLC. Uniformity of the dispersed phase is interpreted as being due to phase separation proceeding in parallel with cure, which will be different from the situation if a solvent was evaporating to form a polymer film. As crosslinks form, the arrangements (configurations) available to the mesogens are reduced and so entropy decreased. Solubility is reduced by the reducing entropy and the mesogens will separate uniformly from the curing epoxy and form small droplets that are fixed in place within the resin cured. Figure 15(a) shows cholesteryl nonanoate dispersed in UV15 at room temperature prior to heating. The dark region represents the polymer matrix while the coloured region represents the solid crystal domains whose texture is similar to that observed in the cholesteryl

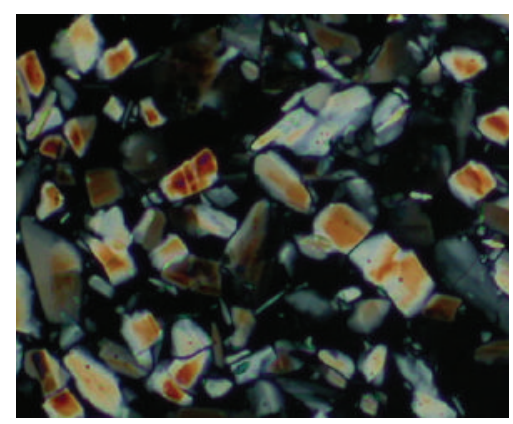

(a)

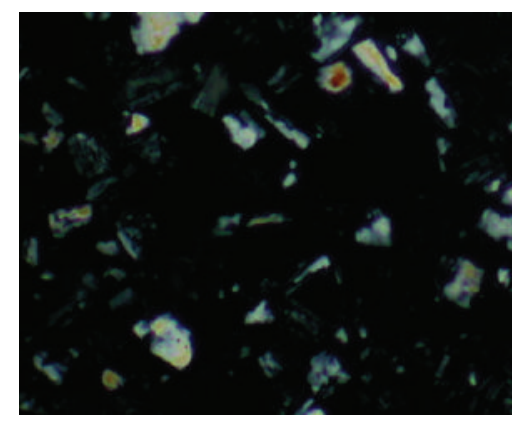

(b)

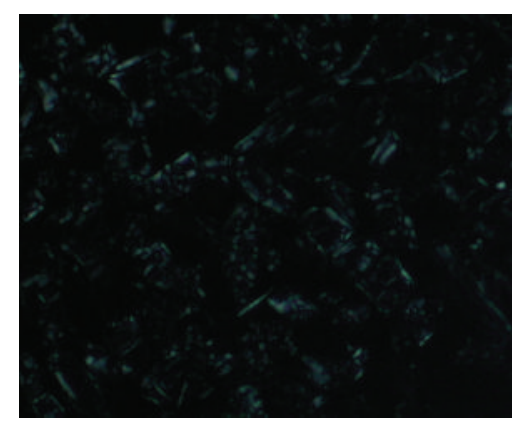

(c)

FIGURE 15: Polarized optical micrographs of cholesteryl nonanoate dispersed in UV15 taken during heating from the solid phase at (a) $25^{\circ} \mathrm{C}$, (b) $65.1{ }^{\circ} \mathrm{C}$, and (c) $75.7^{\circ} \mathrm{C}$.

acetate-UV15 PDLC. Figures 15(b) and 15(c) show the transition from the solid to the mesophase at $65.1^{\circ} \mathrm{C}$ and $75.7^{\circ} \mathrm{C}$, respectively. A dark field of view was observed after transition to the isotropic phase.

The DSC cooling scan for cholesteryl nonanoate dispersed in UV15 shown in Figure 14(b) shows two supercooled peaks at $80.7{ }^{\circ} \mathrm{C}$ and $56.1{ }^{\circ} \mathrm{C}$ corresponding to the clearing temperature and melting temperature, respectively. The supercooling has resulted from the constrained confinement of the mesogens within droplets in the cured polymer. Figures $16(\mathrm{a})$ and $16(\mathrm{~b})$ taken at $90.4^{\circ} \mathrm{C}$ and $71.6^{\circ} \mathrm{C}$, respectively, show polarized optical microscope images of the transition from isotropic liquid domains to liquid crystal domains. Figure 16(c) shows the solid crystal domains at room temperature after cooling. The solid crystal domains appear to have a marble-like texture after cooling from the isotropic phase. 


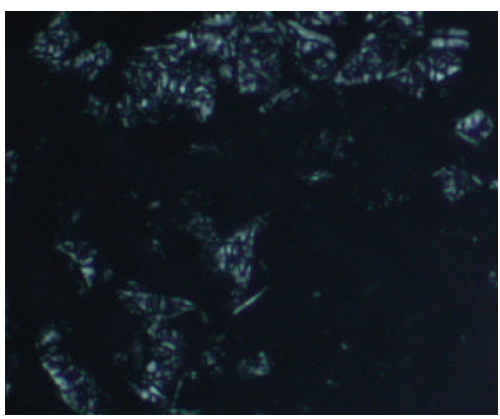

(a)

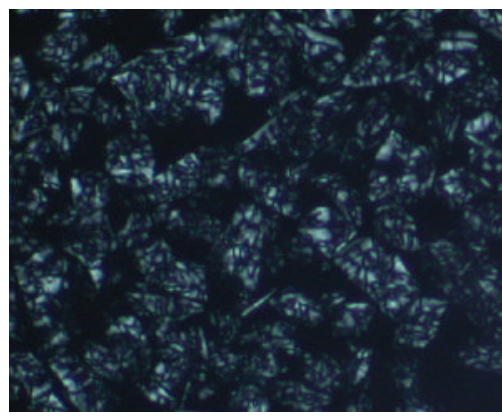

(b)

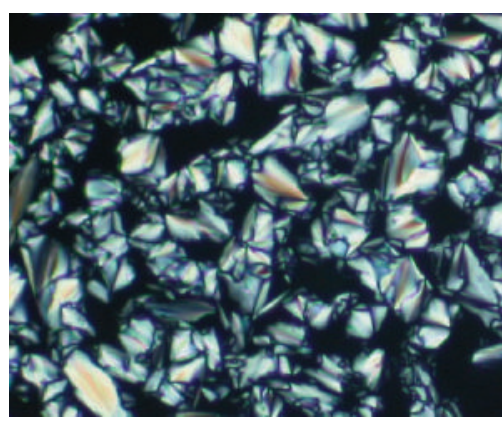

(c)

FIGURE 16: Polarized optical micrographs of cholesteryl nonanoate dispersed in UV15 taken during cooling from the isotropic phase at (a) $90.4{ }^{\circ} \mathrm{C}$, (b) $71.6^{\circ} \mathrm{C}$, and (c) $25^{\circ} \mathrm{C}$.

3.2.3. Cholesteryl Benzoate: UV15. The DSC heating scan for cholesteryl benzoate dispersed in UV15 is shown in Figure 17(a). Polarized optical microscopy identified the peak shown on the DSC heating scan at $125.1{ }^{\circ} \mathrm{C}$ as the melting temperature eliminating the possibility of the peak at $111.4^{\circ} \mathrm{C}$ being the transition from solid to liquid crystal as there was no identifiable mesophases region observed prior to the isotropic liquid forming at $125^{\circ} \mathrm{C}$.

The DSC cooling scan for cholesteryl benzoate dispersed in UV15 shown in Figure 17 (b) shows a peak at $88.4^{\circ} \mathrm{C}$ corresponding to the supercooled clearing temperature resulting from mesogen confinement. The peak for the crystallization temperature is not seen as it is overlapping with the peak for the clearing temperature. Through the use of polarized optical microscopy, the crystallization temperature was found to be $79.9^{\circ} \mathrm{C}$. The polarized optical microscopy images in Figures 18 (a) and $18(\mathrm{~b})$ at $100.5^{\circ} \mathrm{C}$ and $85.4^{\circ} \mathrm{C}$, respectively,

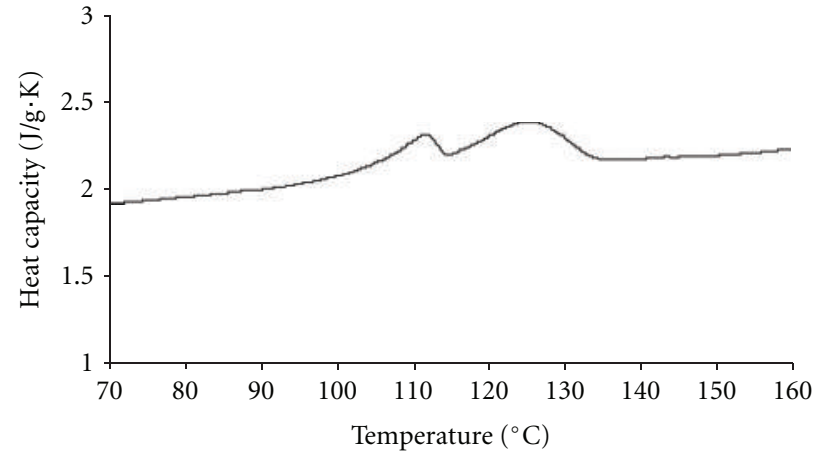

(a)

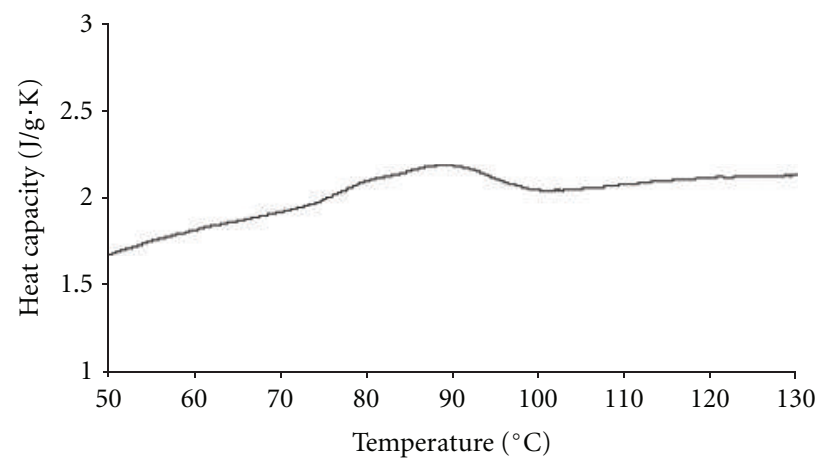

(b)

FIGURE 17: DSC thermograms for cholesteryl benzoate dispersed in UV15 at scanning rate of $10 \mathrm{~K} \cdot \mathrm{min}^{-1}$, (a) heating, (b) cooling.

show the transition from isotropic liquid domains to the liquid crystal domains. The liquid crystal domains were observed to be very irregular in shape and size when compared with those produced using cholesteryl acetate and cholesteryl nonanoate. Figure 18(c) shows the solid crystal domains at room temperature after cooling.

\section{Conclusion}

The optical and thermal characterization of polymerdispersed liquid crystals and their mesogenic components were characterised using differential scanning calorimetry and hot-stage polarized optical microscopy. PDLCs were prepared by polymerisation-induced phase separation. Liquid crystallinity was observed in all polymer-dispersed liquid crystals produced and their mesogenic components. The liquid crystals, both as mesogenic moieties and as dispersed droplets within the epoxy-acrylate matrix, exhibited various textures according to their molecular order and orientation. These textures formed in confined regions separated by phase boundaries that occurred at temperatures unique to each liquid crystal.

Cholesteryl acetate exhibited a disturbed cholesteric texture on cooling from the isotropic phase. 4(Decyloxy)benzoic acid passed through a number of mesophases between the solid and isotropic states, both on heating and cooling. Polymorphism was exhibited by 4-(decyloxy)benzoic acid, with textures exhibited by both 


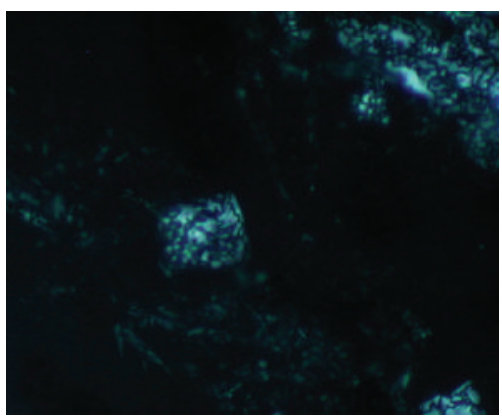

(a)

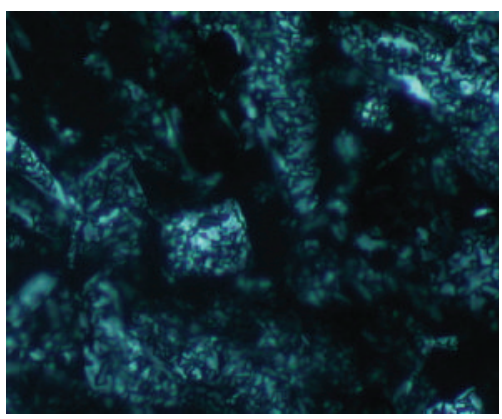

(b)

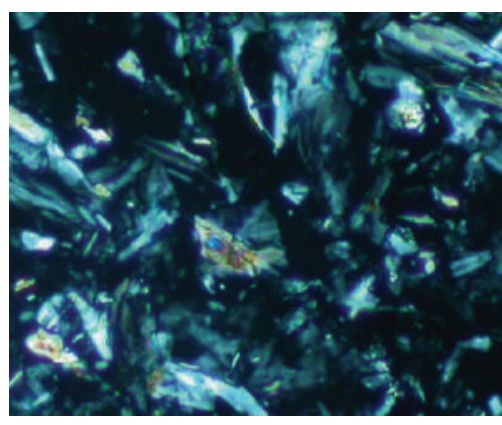

(c)

FIGURE 18: Polarized optical micrographs of cholesteryl benzoate dispersed in UV15 taken during cooling from the isotropic phase at (a) $100.5^{\circ} \mathrm{C}$, (b) $85.4^{\circ} \mathrm{C}$, and (c) $25^{\circ} \mathrm{C}$.

nematic and smectic ordering identified. These textures included Schlieren and marbled nematic textures and twisted smectic texture. Cholesteryl nonanoate exhibited a cholesteric texture on heating and a smectic texture followed by a homeotropic texture on cooling. Cholesteryl benzoate exhibited a disturbed cholesteric texture on cooling from the isotropic phase.

Differential scanning calorimetry (DSC) showed the phase transition temperatures for the liquid crystal droplets within the polymer matrices to be lower than the respective phases transition temperatures for the mesogens in the neat state due to spatial confinement and an interphase of adsorbed mesogen at the droplet boundaries. For cholesteryl acetate and cholesteryl nonanoate PDLC, the morphology of the liquid crystal domains was observed to be much more uniform in shape and size when compared with cholesteryl benzoate PDLC where the liquid crystal domains were seen to be irregular in shape and size. The textures produced by the PDLC were different to those produced by the neat mesogens and were exhibited over different temperature ranges. Cholesteryl acetate and cholesteryl nonanoate PDLC exhibited liquid crystal mesophases on both heating and cooling. Cholesteryl benzoate PDLC exhibited liquid crystallinity only on cooling from the isotropic phase. The mesophases exhibited by PDLC were of the same texture, varying only in colour.

\section{References}

[1] E. B. Priestly, "Liquid crystal mesophases," in Introduction to Liquid Crystals, E. B. Priestly, P. J. Wojtowicz, and P. Sheng, Eds., chapter 1, pp. 1-13, Plenum Press, New York, NY, USA, 1975.

[2] A. W. Levine, "Property relationships in thermotropic organic liquid crystals," in Introduction to Liquid Crystals, E. B. Priestly, P. J. Wojtowicz, and P. Sheng, Eds., chapter 2, pp. 15-28, Plenum Press, New York, NY, USA, 1975.

[3] C. Noel, "Identification of mesophases exhibited by thermotropic liquid crystalline polymers," in Polymeric Liquid Crystals, A. Blumstein, Ed., pp. 21-59, Plenum Press, New York, NY, USA, 1983.

[4] M. Abramowitz, Microscope Basics and Beyond, vol. 1, Olympus America, 2003.

[5] H. Kelker and R. Hatz, Handbook of Liquid Crystals, chapter 1, Chemie, Weinheim, Germany, 1980.

[6] A. C. Griffin, S. R. Vaidya, and M. L. Steele, "Liquid crystalline polymers: phenomenological and synthetic aspects," in Polymeric Liquid Crystals, A. Blumstein, Ed., chapter 1, Plenum Press, New York, NY, USA, 1985.

[7] G. W. Gray and B. Jones, "The mesomorphic transition points of the p-n-alkoxybenzoic acids. a correction," Journal of the Chemical Society, pp. 4179-4180, 1953.

[8] C. Weygand and R. Gabler, "The higher homologues of Azophenol, Azoxyphenol and Azomethylenephenol ether," Zeitschrift für Physikalische Chemie, vol. 46, p. 270, 1940.

[9] R. S. Porter and J. F. Johnson, "Liquid crystals," in Liquid Crystals and Ordered Fluids, G. H. Brown, G. J. Diene, and M. M. Labes, Eds., chapter 2, Plenum Press, New York, NY, USA, 1966.

[10] G. W. Gray and B. Jones, "Mesomorphism and chemical constitution. Part IV. The effect of substitution on the mesomorphism of the 6-n-alkoxy-2-naphthoic acids," Journal of the Chemical Society, pp. 236-244, 1955.

[11] L. K. Knaak, H. M. Rosenberg, and M. P. Serve, "Estimation of Nematic-Isotropic Points of Nematic Liquid Crystals," Molecular Crystals and Liquid Crystals Science and Technology, vol. 17, p. 171, 1972.

[12] G. W. Gray and B. Jones, "Mesomorphism and chemical constitution. part ii. the trans-p-n- alkoxycinnamic acids," Journal of the Chemical Society, pp. 1467-1470, 1954.

[13] I. Heynderickx and D. Broer, "Thermo-Optical Properties of a Polymer Dispersed Liquid Crystalline Polymer," Molecular Crystals and Liquid Crystals Science and Technology, vol. 263, pp. 415-427, 1995.

[14] D. Yang, J. Lin, T. Li, S. Lin, and X. Tian, "Effect of external electrical field on phase behavior and morphology development of polymer dispersed liquid crystal," European Polymer Journal, vol. 40, p. 1823, 2004. 
[15] G. M. Russell, B. J. A. Paterson, C. T. Imrie, and S. K. Heeks, "Thermal characterization of polymer-dispersed liquid crystals by differential scanning calorimetry," Chemistry of Materials, vol. 7, no. 11, pp. 2185-2189, 1995.

[16] H. M. Siddiqi, M. Dumon, and J. P. Pascault, "Polymer dispersed liquid crystals based on epoxy networks: transformations and phase separation phenomena during polycondensation," Molecular Crystals and Liquid Crystals Science and Technology Section A, vol. 312, pp. 137-155, 1998.

[17] W. Ahn and K. Ha, "Temperature effects on lc droplets formation of pdlc films with thermoplastic matrix," Korea Polymer Journal, vol. 7, no. 2, pp. 130-135, 1999.

[18] K. Amundson, A. Van Blaaderen, and P. Wiltzius, "Morphology and electro-optic properties of polymer-dispersed liquidcrystal films," Physical Review E, vol. 55, no. 2, pp. 1646-1654, 1997.

[19] S. A. Carter, J. D. LeGrange, W. White, J. Boo, and P. Wiltzius, "Dependence of the morphology of polymer dispersed liquid crystals on the uv polymerization process," Journal of Applied Physics, vol. 81, no. 9, pp. 5992-5999, 1997.

[20] W.-K. Chin, L.-P. Hsin, H.-L. Lu, and M.-D. Shau, "Morphology of epoxy/acrylic polymer-dispersed liquid-crystal film in DICY thermal cure," Journal of Polymer Science, Part B, vol. 38, no. 15, pp. 2033-2042, 2000.

[21] L. Lucchetti, L. Gobbi, and F. Simoni, "Analysis of the phase separation process in uv cured polymer dispersed liquid crystals for optical applications," Molecular Crystals and Liquid Crystals Science and Technology, Section A, vol. 359, pp. 89-96, 2001. 

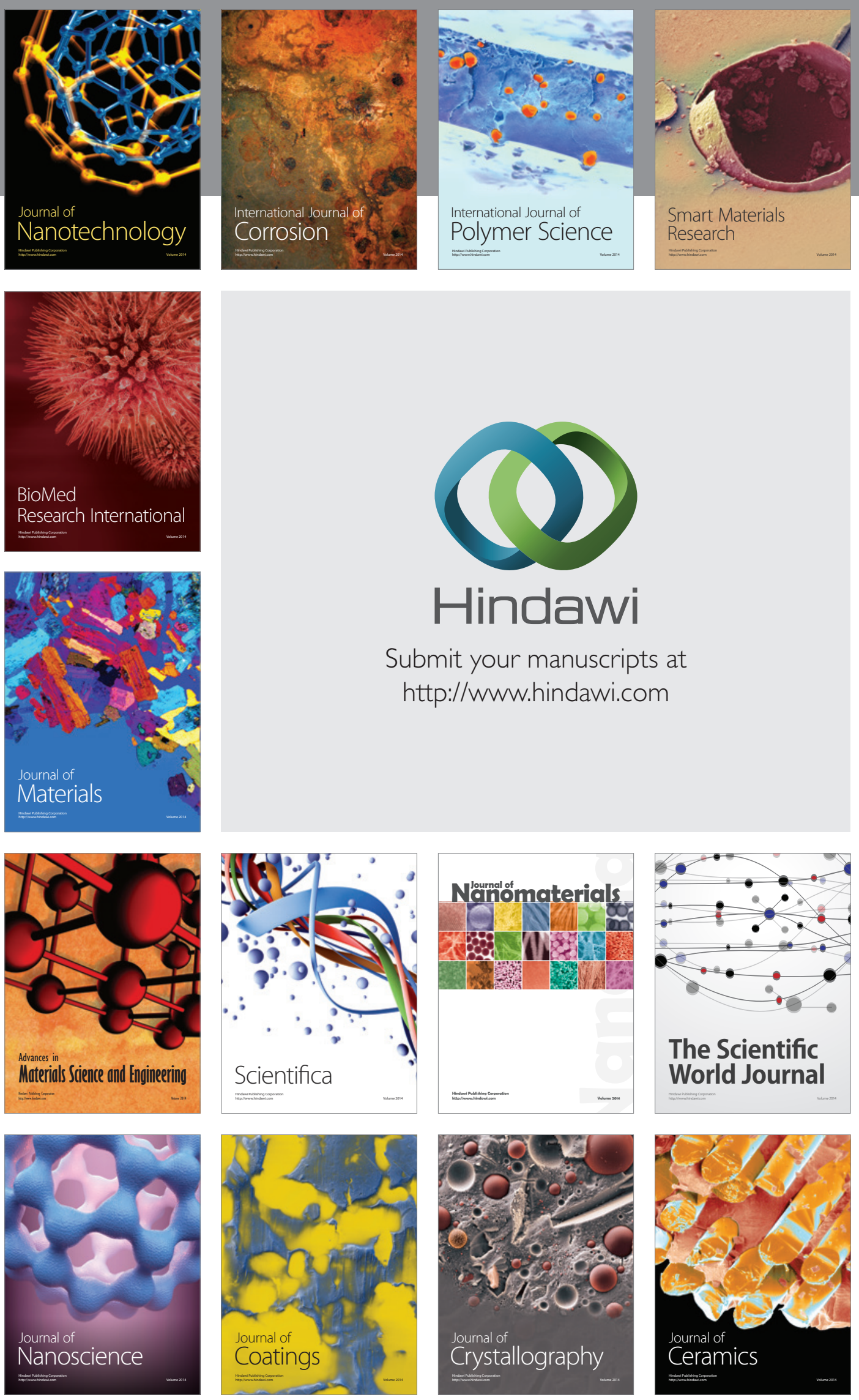

The Scientific World Journal

Submit your manuscripts at

http://www.hindawi.com

\section{World Journal}

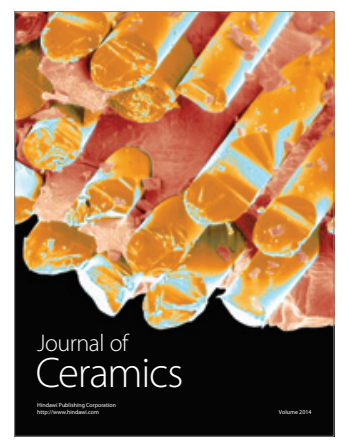

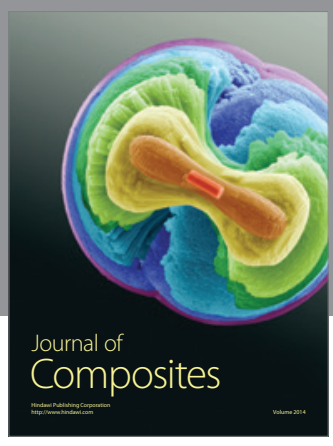
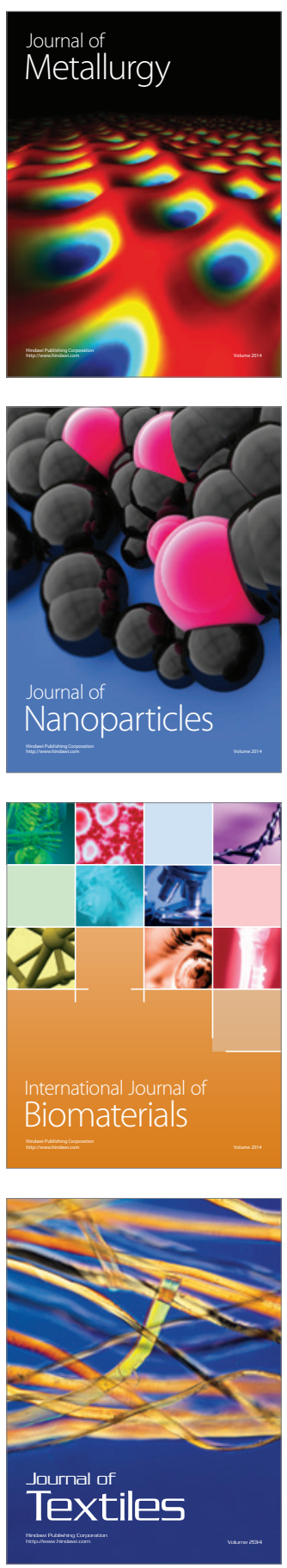